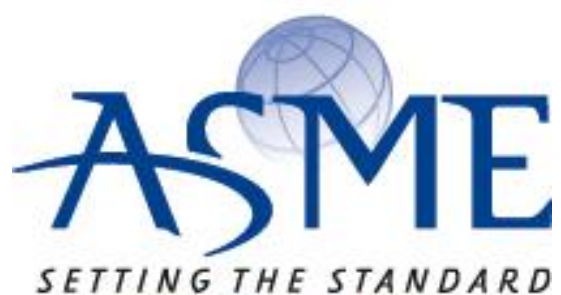

SETTING THE STANDARD

\section{American Society of Mechanical Engineers}

ASME Accepted Manuscript Repository

Institutional Repository Cover Sheet

ASME Paper Title: Design of a Test Platform for the Determination of Lithium-Ion Batteries State of Health.

Authors:

Jules-Adrien Capitaine and Qing Wang

ASME Journal Title: Journal of Mechanical Design

Date of Publication (VOR* Online)

Volume/Issue $141 / 2$ -20/12/2018

ASME Digital Collection URL: https://mechanicaldesign.asmedigitalcollection.asme.org

DOI:

*VOR (version of record) 


\title{
Design of a test platform for the determination of Lithium-ion Batteries state of health
}

\author{
Jules-Adrien Capitaine, \\ Department of Engineering, Durham University \\ South Road, Durham, DH1 3LE U.K. \\ julesadrien.capitaine@gmail.com \\ Qing Wang ${ }^{1}$ \\ Department of Engineering, Durham University \\ South Road, Durham, DH1 3LE U.K. \\ Qing.wang@durham.ac.uk
}

\begin{abstract}
This paper presents a novel design for a test platform to determine the State of Health (SOH) of lithium-ion batteries. The $\mathrm{SOH}$ is a key parameter of a battery energy storage system and its estimation remains a challenging issue. The batteries that have been tested are 18650 li-ion cells as they are the most commonly used batteries on the market. The test platform design is detailed from the building of the charging and discharging circuitry to the software. Data acquired from the testing circuitry is stored and displayed in LabView to obtain the charging and discharging curves. The resulting graphs are compared to the outcome predicted by the battery datasheets, to verify that the platform delivers coherent values. The $\mathrm{SOH}$ of the battery is then calculated using a Coulomb Counting method in LabView. The batteries will be discharged through various types of resistive circuits, and the differences in the resulting curves will be discussed. A single battery cell will also be tested over 30 cycles and the decrease in the SOH will be clearly identified.
\end{abstract}

\footnotetext{
${ }^{1}$ Corresponding author
} 
Journal of Mechanical Design

\section{INTRODUCTION}

Lithium-Ion batteries (LIB) have become a power source of choice in the electronics market and are currently produced at a rate of billions of units per year [1]. This growing interest in LIBs is due to their portability, hence their use in devices such as laptops, tablets and phones, as well as their high specific energy. Their specific energy is situated between 100 and 200Wh/kg, whereas lead acid, $\mathrm{NiCd}$ and $\mathrm{NiMH}$ batteries obtain approximately $10-50 \mathrm{Wh} / \mathrm{kg}, 25-70 \mathrm{Wh} / \mathrm{kg}$ and $70-100 \mathrm{Wh} / \mathrm{kg}$ respectively [2]. Moreover, the recent need of renewable energies is giving LIBs a new field of application: electric vehicles. Even if today's electric vehicle batteries reach on average $0.1 \mathrm{kWh} / \mathrm{kg}$, it is expected from recent research that they could soon equal the energy delivered by gasoline, that is to say around $1.7 \mathrm{kWh} / \mathrm{kg}$ [3]. As a matter of fact, in 2015, more than 3,000 million hybrid electric vehicles were sold worldwide, and more than $15 \%$ of the batteries were LIBs [1].

Despite their great specific energy, the inner chemical composition of a LIB induces a natural degradation of the cell [4]. The main phenomenon at the source of the aging of the cell is called the solid-electrolyte interphase (SEI). This phenomenon causes the formation of a protective film on the anode surface and leads eventually to a decrease in the number of active lithium, and thus to an irreversible capacity loss [5]. Thus, the measurement of the battery capacity is essential in the determination of the state of the battery.

As Isodor Buchmann explained in his handbook [2], 90\% of the cell phone batteries that are returned under warranty to the manufacturer have no problems. This phenomenon is due to a misjudgment of the actual causes of the cell phone failure. It is 
Journal of Mechanical Design

often thought that the battery is the source of the failure, when in lots of cases it is not. Thus, work still needs to be done towards the determination of the health of LIB cells.

This paper focuses on this determination via the designing of a test platform for Lithium-ion batteries. It will answer the issue of a need for evaluating the remaining energy left in these batteries. The batteries that are going to be tested are 18650 LIB cells, which are the most commonly used LIBs on the portable electric devices and electric vehicles markets [6].

A circuitry has first been built in order to test both the charge and discharge of the battery. The charging circuitry has been designed to charge the battery in a constant current-constant voltage (CC-CV) mode, which allows the full charge of the battery [5]. As the battery charges, the voltage and current are measured. Once the charge is completed, the battery will be discharged. The transition from charge to discharge is achieved by a simple analogue switch.

The discharge is carried out by a circuitry composed of a DC/DC converter connected to a charging circuit. The discharge of the battery will enable another battery to be charged. The LIB will also be discharged through a resistance by which current and voltage will be measured. These measurements will provide the discharging curves from which the total capacity of the battery will be extracted.

The different measurements will be carried out by a DAQ data acquisition system connected to a computer. This DAQ will also allow the control of the analogue switch chip. The software LabView is used to control the DAQ. A block diagram has been designed in the software to regulate the running of the test platform. Thus, data 
Journal of Mechanical Design

acquired by the DAQ are displayed on waveforms, and the conditions on the measurements will determine the working of the analogue switch.

\section{THEORY}

\subsection{Charging and discharging methods}

LIBs can be charged in different ways. However, there is one method of charging that is more widely used and provides a better charge of the battery: the Constant Current-Constant Voltage charging (CC-CV) [7]. This method consists of charging the battery at a constant current until the maximum set voltage is reached (usually $4.2 \mathrm{~V}$ ). The value of the constant current determines the rate of charge. For instance, a battery with a capacity of $2000 \mathrm{mAh}$ charged with a constant current of $1 \mathrm{~A}$ is charged at a rate of $0.5 \mathrm{C}$. Then, the charge current slowly decreases while the current stays constant at 4.2V. CC-CV will be used in order to gauge the actual capacity of the battery as it charges to the fullest capacity.

To discharge the battery, a simple resistor circuit can be put in place. However, some precautions have to be taken as the current passing through a resistor induces a production of heat that can cause the resistor to deteriorate. It will be seen in the next part that calculations have been carried out to determine what type of resistor to install. Moreover, several articles $[6,8,9]$ note that an LIB cell should not reach voltages under $3 \mathrm{~V}$ or they could severely deteriorate with irreversible damages. That is why every battery will only be discharged until their output voltage is 3V.

\subsection{Battery state of health}

The age of the battery is usually determined by the $\mathrm{SOH}$. The $\mathrm{SOH}$ is a percentage that starts at $100 \%$ when the battery is new and decreases as the battery 
Journal of Mechanical Design

ages [10]. This parameter cannot be measured directly while the battery operates in an electric device [11], hence the building of a test platform that will be described in the next part of this paper. Different methods can be used to calculate a battery's SOH. They can be grouped into two approaches: experimental techniques and adaptive methods [10]. For each method, their advantages, disadvantages and corresponding literature are presented in Table 1.

Table 1. SOH estimation methods

\begin{tabular}{|c|c|c|c|}
\hline & Method & Advantages and Disadvantages & References \\
\hline \multirow[t]{7}{*}{$\begin{array}{l}\text { Experimental } \\
\text { Techniques }\end{array}$} & $\begin{array}{l}\text { Coulomb } \\
\text { counting }\end{array}$ & $\begin{array}{l}\text { A: the number of Ah can be counted, therefore the battery capacity can } \\
\text { be obtained } \\
\text { D: high computation time and accumulative errors it carries during the } \\
\text { counting }\end{array}$ & {$[12-13]$} \\
\hline & $\begin{array}{l}\text { Electrochemical } \\
\text { impedance } \\
\text { spectroscopy }\end{array}$ & $\begin{array}{l}\text { A: using this method can estimate the actual value of the impedance } \\
\text { D: there are significant variations of battery resistance/impedance } \\
\text { among different battery types, therefore costly to implement }\end{array}$ & [14-16] \\
\hline & $\begin{array}{l}\text { Internal } \\
\text { resistance } \\
\text { measurement }\end{array}$ & $\begin{array}{l}\text { A: can evaluate resistance degradation to indicate battery life } \\
\text { D: a significant number of curves are needed to be able to calculate } \\
\text { resistance }\end{array}$ & {$[17-18]$} \\
\hline & $\begin{array}{l}\text { Probabilistic } \\
\text { method }\end{array}$ & $\begin{array}{l}\text { A: uses classical probability theory, saves computation time } \\
\text { D: not able to account for the influence of temperature fluctuations } \\
\text { experienced by batteries. }\end{array}$ & [19] \\
\hline & $\begin{array}{l}\text { Support vector } \\
\text { regression } \\
\text { algorithm }\end{array}$ & $\begin{array}{l}\text { A: uses regression algorithm for } \mathrm{SOH} \text { estimation } \\
\text { D: large amount of data needs to be collected to ensure the accuracy of } \\
\text { SOH estimation }\end{array}$ & {$[20-21]$} \\
\hline & $\begin{array}{l}\text { Failure } \\
\text { detection }\end{array}$ & $\begin{array}{l}\text { A: used to measure the mechanical failure of the battery } \\
\text { D: failure information needs to be combined with other conventional } \\
\text { algorithms to achieve reliable results }\end{array}$ & {$[22-23]$} \\
\hline & Big data & $\begin{array}{l}\text { A: large amount data collected can expose variability and boost battery } \\
\text { performance } \\
\text { D: how to deal with the data to develop an accurate measurement } \\
\text { algorithm remains a problem }\end{array}$ & {$[24]$} \\
\hline \multirow[t]{4}{*}{$\begin{array}{l}\text { Adaptive } \\
\text { methods }\end{array}$} & $\begin{array}{l}\text { Extended } \\
\text { Kalman filter }\end{array}$ & $\begin{array}{l}\text { A: can produce accurate results. } \\
\text { D: constant tracking of the battery states is needed }\end{array}$ & {$[25-26]$} \\
\hline & Fuzzy logic & $\begin{array}{l}\text { A: uses rule of the fuzzy logic theory to categorize the measured data as } \\
\text { crisp and fuzzy sets } \\
\text { D: requires a large amount of testing data and computation time is high }\end{array}$ & [27] \\
\hline & $\begin{array}{l}\text { Artificial neural } \\
\text { networks }\end{array}$ & $\begin{array}{l}\text { A: simplifies the modelling process and can handle data with nonlinear } \\
\text { dependencies } \\
\text { D: implementation cost is high }\end{array}$ & {$[28]$} \\
\hline & Least squares & $\begin{array}{l}\text { A: uses least squares algorithm to identify the coefficients of the } \\
\text { parameters of the battery model } \\
\text { D: method needs to be validated at different temperatures }\end{array}$ & {$[29-30]$} \\
\hline
\end{tabular}


Journal of Mechanical Design

One popular method is called Electrochemical Impedance Spectroscopy (EIS). It consists of modelling the battery by an equivalent circuit composed of several parallel $\mathrm{RC}$ networks and determining the impedance of the battery as a function of frequency. This method is described in the studies [11,31,32,33,34]. However, although this method tends to be very accurate, it has been revealed to be quite complex in practice and demands a high level of computation [35].

It is required from this research project to have the simplest and most efficient method to estimate the age, and thus the $\mathrm{SOH}$, of lithium-ion batteries. The Coulomb counting (CC) method is one of the most used methods. According to [10], the CC method is not the most accurate but still has an accuracy above $90 \%$. It is mostly used for its simplicity: during the charging and discharging of the LIB, the transferred amount of $A h$ is counted, allowing the remaining capacity to be known. The equation to estimate the $\mathrm{SOH}$ with this method is:

$$
S O H=\frac{Q \max }{\text { Qnominal }} \times 100 \%
$$

Where Qmax is the maximum capacity measured when the battery is fresh and Qnominal is the measured capacity [10].

The CC method calculates the remaining capacity by accumulating the charge transferred in or out of the battery. Although this simple method requires a long time for monitoring and memorizing, it is critical for verifying the accuracy of estimated results from other methods.

The threshold for an LIB is $80 \%$ [9]. Thus, when the battery has an $\mathrm{SOH}$ of $80 \%$ or less, it is considered to have reached its end-of-life and cannot be used any longer in 
Journal of Mechanical Design

electric devices. The $\mathrm{SOH}$ determination carried out here will be used to situate the battery in its life cycle and to know if the battery is still usable.

\section{Method}

This part describes the design of the test platform. Several tools have been used to build it. This way, a circuit has been built to carry out the charge and discharge of an LIB cell. The design of the software will also be explained to show how the control of the circuit, as well as the measurements, are managed.

\subsection{Charging circuit}

The first step in the designing of the test platform was the building of the circuitry. The circuitry is composed of two main parts: the charging and the discharging circuits. The charging circuit had to charge the battery using the CC-CV method. Thus, the microchip MCP73833 [36] was used: it employs a CC-CV charge algorithm and fixes the constant voltage regulation at $4.20 \mathrm{~V}$. It also contains a thermal regulation that limits the charge current, optimizing the charge cycle time while maintaining reliability.

Figure 1 presents the charging circuit. The VDD input of the chip must be connected to a $5 \mathrm{~V}$ power source. Three LEDs connected to the ports STAT1, STAT2 and PG are used to inform the user if the power current is valid and if the battery is charging or fully charged. The $10 \mathrm{k}$ thermistor is there for temperature monitoring purposes: it ensures the temperature of the battery does not go above $45^{\circ} \mathrm{c}$.

Thus, the circuit will deliver a constant current of $1 \mathrm{~A}$ to the battery, and then a constant voltage of $4.2 \mathrm{~V}$. When the charge is completed, the current drops to $0 \mathrm{~A}$.

As Figure 1 also shows, the charging circuitry is not directly connected to the LIB, as the output current must first pass through the analogue switch, which will have 
further explanation in the design of the software part. It is controlled by the software and connects the LIB to either the port S1 or S4 depending on what is required. If the LIB is to be charged, the analogue switch will be placed in position S4, allowing the output current from the circuit to charge the battery.

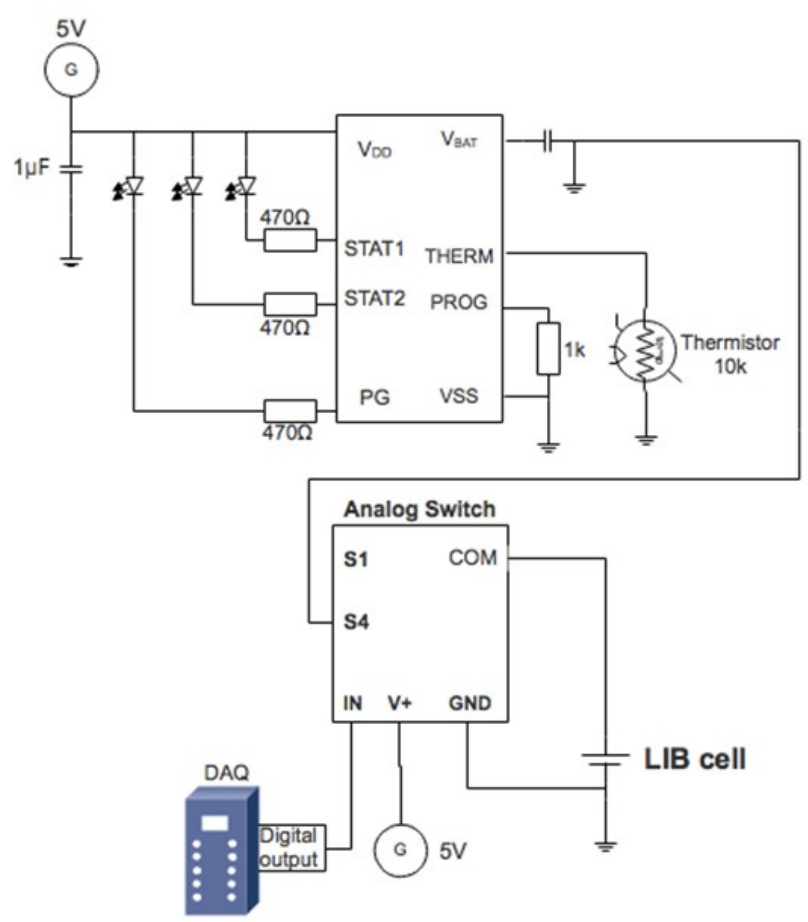

Fig.1 Charging circuit design

\subsection{Discharging circuit}

The discharging circuit presents several options. The first goal of this part of the circuit is to discharge the battery, but it is also interesting to have the possibility to discharge the battery at different rates so that the $\mathrm{SOH}$ test platform can be adapted for different uses of the battery. Thus, the battery will be discharged through either a $4.5 \Omega$, $9 \Omega$ or $15 \Omega$ resistor circuit. Nevertheless, some considerations must be taken into account to build these resistor circuits. Indeed, the passage of current through the resistor produces heat. The physical ability of the resistor to withstand, without 
Journal of Mechanical Design

deterioration, the temperature attained limits the operating temperature that can be permitted. The resistor circuits are built with $1 / 2$ watt resistors, that is to say resistors that can only manage a maximum heat production of 0.5 watt. Thus, some calculation must be done in order to know what and how many resistors to put on the circuits.

As the batteries will be charged up to $4.2 \mathrm{~V}$, the maximum voltage in each case will be $4.2 \mathrm{~V}$. Concerning the $15 \Omega$ discharging circuit, the maximum voltage going through the circuit is $\max =U \max / \mathrm{R}=4.2 \mathrm{~V} / 15 \Omega=0.28 \mathrm{~A}$. A single resistor of $15 \Omega$ could not bear the heat rise that would be caused by the current passage. The heat produced can be calculated by the formula $\mathrm{P}=\mathrm{RI}^{2}$, and is here equal to $1.18 \mathrm{~W}$, which is largely superior to $0.5 \mathrm{~W}$. The minimum resistive value can be found by $\mathrm{Rmin}=\mathrm{Pmax} / \mathrm{I}^{2}=0.5 / 0.28^{2}=6.38 \Omega$. It has thus been decided to put three $5 \Omega$ resistors in series for this $15 \Omega$ discharging circuit.

Concerning the other resistor circuits, the same technique has been used. The $9 \Omega$ circuit has a maximum current of $0.47 \mathrm{~A}$, and needs an assembly of resistors with a minimum value of $\operatorname{Rmin}=0.5 / 0.47^{2}=2.26 \Omega$. The circuit is thus composed of four $2 \Omega$ resistors and one $1 \Omega$ resistor. Finally, the $4.5 \Omega$ circuit has a maximum current of $0.93 \mathrm{~A}$ and a minimum resistor value of $\operatorname{Rmin}=0.5 / 0.93^{2}=0.58 \Omega$, which induces the circuit to be composed of nine $0.5 \Omega$ resistors.

Moreover, another discharging circuit has been built. The principle of this circuit was to use the discharge of an LIB to charge another one. A second charging circuit similar to the one described in the first paragraph has thus been built. However, as seen previously, the charging circuit requires a voltage of $5 \mathrm{~V}$ to be powered, and a fully 
Journal of Mechanical Design

charged battery has a starting voltage of $4.2 \mathrm{~V}$. This weak voltage will not be able to power the charging circuit. That is why a DC/DC converter has been added to the circuit. The chip LT1308A [37] has been used. It operates over a $1 \mathrm{~V}$ to $10 \mathrm{~V}$ input range. The datasheet proposes a circuit that can be used to convert the voltage out of a single LIB cell to $5 \mathrm{~V}$ and $1 \mathrm{~A}$. Thus, the output current of the $\mathrm{DC} / \mathrm{DC}$ converter can power the charging circuitry for the discharged LIB cell. Figure 2 shows a schematic diagram of the discharging circuitry that has been built.

However, as it will later be discussed, this discharging method is not conclusive as the energy drawn out of the first cell is mostly lost in the circuit, and a very small charge of the second cell is achieved.

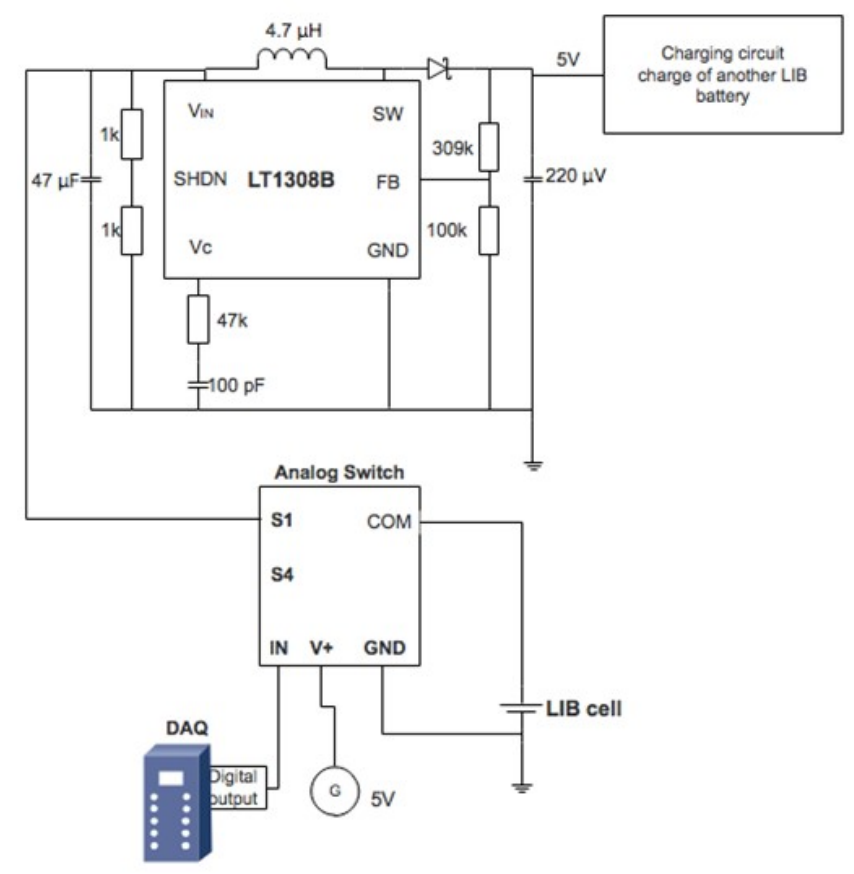

Fig.2 Discharging circuit design 
Journal of Mechanical Design

\subsection{Analogue switch}

The analogue switch is the TS5A3157 chip [38]. As Figures 1 and 2 illustrate, it has six ports, including a GND and a V+ port that must be respectively connected to the negative and positive ports of a $5 \mathrm{~V}$ power source. The COM port is connected to the LIB cell, which will either be charged or discharged depending on the position of the switch, as S4 and S1 are respectively connected to the charging and discharging circuit.

The position of the switch is controlled by the input IN. If it receives a "high" input, that is to say a voltage superior to $1 \mathrm{~V}, \mathrm{COM}$ is connected to $\mathrm{S} 1$, and if it receives a voltage close to $\mathrm{OV}, \mathrm{COM}$ is connected to $\mathrm{S} 4$. This analogue switch will be controlled by the software that will be studied in detail in the next paragraph.

\subsection{Software design}

The software part of the test platform has been designed using LabView [39]. It allows a simple and clear aspect thanks to two main windows [40]: a control window on which are presented the different waveforms, tables or any other indicators that have been chosen to look at the measurements, and a block diagram window. This block diagram is the code designed to acquire the measurements and control the process of the test platform. The two parts of the block diagram (measurements and control) are studied more precisely in the following two paragraphs. Figure 3 presents the software design for the charging part of the circuit. 


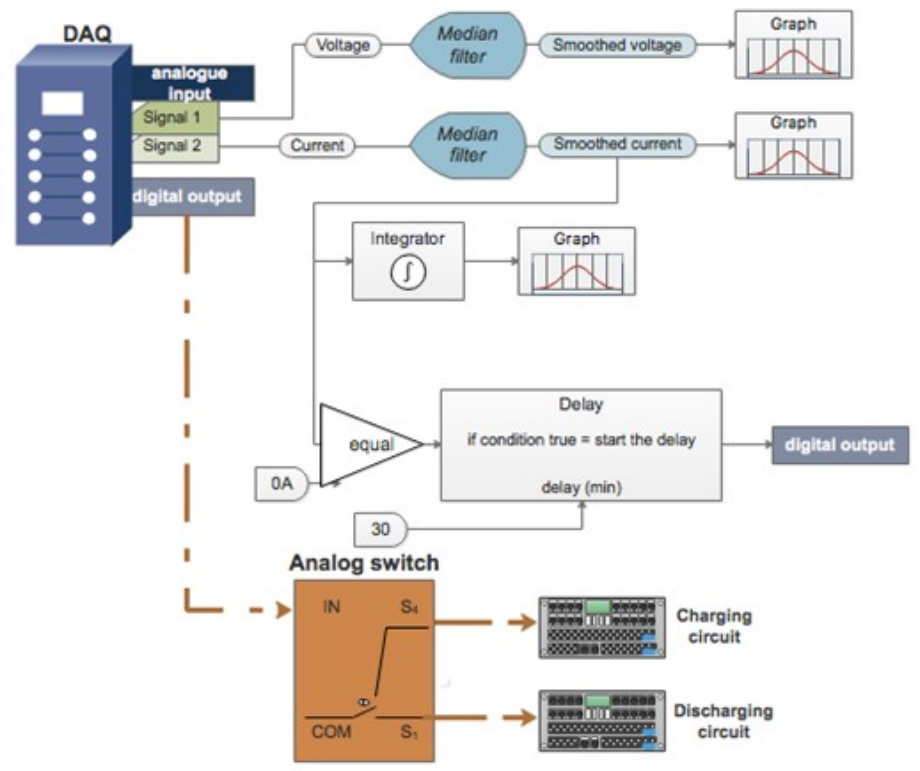

Fig.3 Charging part of the software design

\subsubsection{Measurement and data processing}

The first part of the software is the one taking care of the measurements. It must acquire the data needed for the analysis. As the battery cell charges, it is interesting to measure the evolution of the output voltage as well as the current. A data acquisition system (DAQ) has been used to measure and to control the analogue switch. This DAQ is composed of several digital input ports as well as analogue outputs. It can be called in the block diagram. The different signals, as shown in Figure 3, are displayed in graphs and tables so that they can later be imported in Excel for analysis.

In both the charging and discharging circuits, the voltage and current (respectively, out and in) of the battery are measured. The first digital input is thus connected to the positive and negative ports of the LIB connected to the charging circuit and acquires the voltage. The second input acquires the current out of the charging 
Journal of Mechanical Design

circuit and passing through the battery. To do that, a resistor has been added between the analogue switch chip and the positive port of the battery. The value of the resistor has been set to $0.5 \Omega$ so that it has a minimal impact on the charging process. Figure 3 shows that the DAQ acquires the data and transmits it to the software in the form of signals that are displayed in graphs. Moreover, the capacity is obtained using an integrator. Ye et al [8], explains how equation (2) can be used to calculate the capacity of a battery over time

$$
Q=\int_{t 1}^{t 2} I d t
$$

where $\Delta \mathrm{T}=\mathrm{t}_{2}-\mathrm{t}_{1}$ is the time spent during the test. Once the signal is integrated, the resulting signal is displayed as a waveform, as well as in a table.

The measurements are carried out continuously to a frequency of $50 \mathrm{~Hz}$. They suffer from noise, so a median filter is used to remove any noise and obtain smoother curves. A median filter is used due to its simplicity and ability to remove "speckles" in the measurement signals while preserving edge information. Compared to linear filter techniques, which tend to blur the image signals, the median filter can provide adequate separation of noise and signal. Figure 4 compares the raw measurements with the data treated by the median filter for the acquisition of the charge of an LIB. The median filter used in LabView is a moving average filter that replaces each data point with the average of the neighbouring data points defined within the span [39]. This process is equivalent to a low-pass filter. 
Journal of Mechanical Design

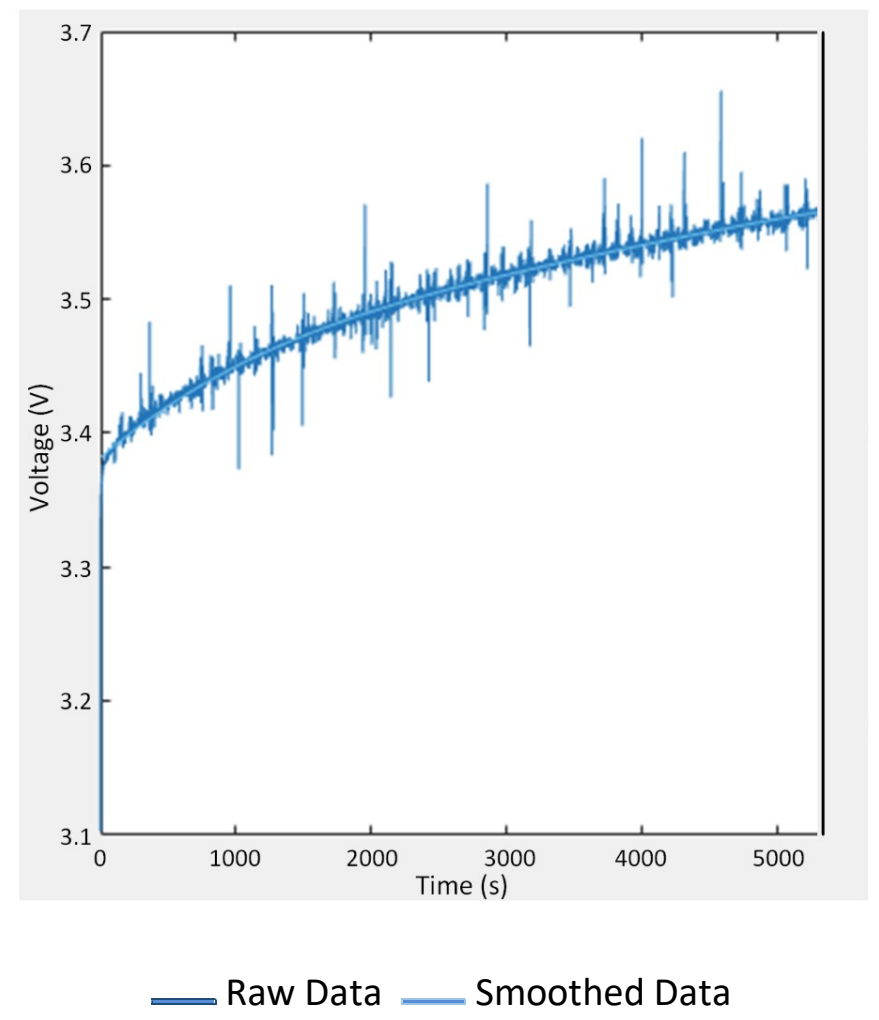

Fig.4 Comparison of raw and smoothed data

The calculation of the $\mathrm{SOH}$ is then carried out with a simple calculation shown by equation (1). The percentage obtained is displayed on the control window so that the user can see the $\mathrm{SOH}$ of the battery at the end of the experiment.

\subsubsection{Analogue switch control}

The other part of the software consists of controlling the analogue switch. The analogue switch fixes which of the charging or discharging circuit has to be driven. The final method that has been designed is described in detail in Figure 5. 


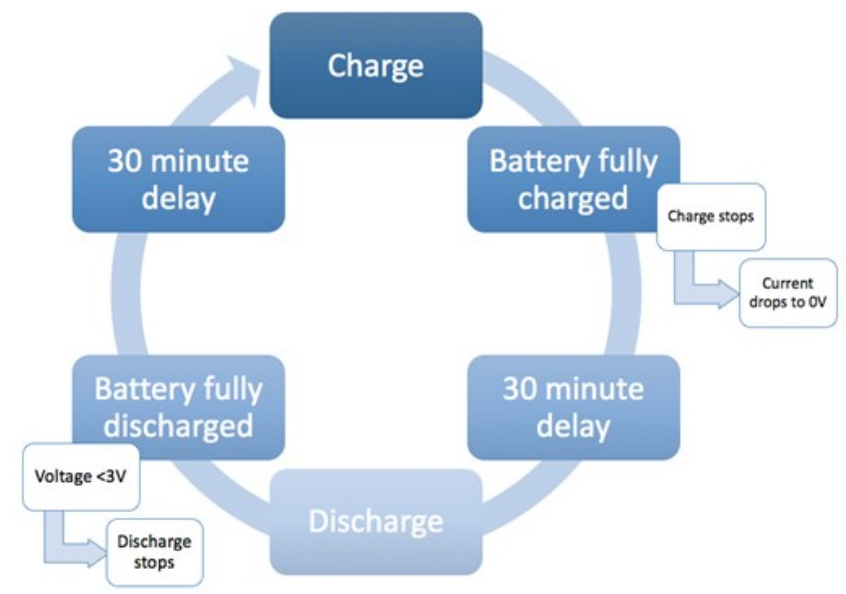

Fig.5 Process of a charging/discharging cycle

The battery is first connected to the charging circuit until it reaches its full charge. Then, once the battery is fully charged, the output current from the chip drops to zero. This information is used to trigger the IN port of the analogue switch, which then changes position to let the discharge begin. This part of the software design is also illustrated in Figure 3: once the current measured from the circuit is equal to $0 \mathrm{~A}$, a delay of 30 minutes occurs before the digital output receives the information "true" and thus triggers the analogue switch connected to its discharging port.

The voltage limit fixed to assess if the discharge is complete is $3 \mathrm{~V}$. Thus, once this criterion is true, the delay block is triggered. It holds the "true" Boolean for thirty minutes and then transmits it to the DAQ system. The analogue output moves then from high to low, triggering the IN input of the analogue switch, which changes position once again and starts another charging cycle. The $\mathrm{SOH}$ will be determined at the end of the discharge. Indeed, once the battery has been discharged and its current has been measured from when it was fully charged, the actual maximum capacity would have been calculated. 
Journal of Mechanical Design

The delay block is important to let the battery voltage settle. As a matter of fact, it will be seen in the results that once it is fully charged or discharged, the output voltage of the battery needs a period of adjustment before it reaches a stable value. It is thus important to let it settle to obtain the most precise results.

\section{Results}

This section presents the different results that have been collected during the experiments. After the test platform was put together, some tests were carried out to verify its processing ability. The batteries that have been used in the different tests are the 18650 battery cells LGC2601016SZ, which have a nominal capacity of $2600 \mathrm{mAh}$. The results extracted from the tests are compared to datasheet outcomes [40].

\subsection{Charging process}

Both charging and discharging circuits were tested several times to obtain different curves of voltage and current against time. Figure $6(a)$ and (b) shows the curves obtained for the charging of an LIB.

As expected, the graphs are composed of two major parts: a first period of constant current charging and a second period with a constant voltage. The chip that had been chosen allows this type of process for a maximum charge of the battery. Thus, the voltage increases sharply in the first couple of seconds to reach a voltage above 4V. It then shows a slower increase, with the slope shallowing progressively until it reaches $4.2 \mathrm{~V}$ where the voltage becomes constant for the rest of the charge.

Concerning the current, the behaviour is about the same at the start as the curve increases suddenly from $\mathrm{OA}$ to approximately 0.9A. After a short period of 
Journal of Mechanical Design

trembling, the current becomes more stable just above 0.9A. At around 6000 seconds, the current starts decreasing at an almost constant rate before dropping to $0 \mathrm{~A}$. It can be noted that the moment the charging process changes to constant voltage corresponds to the moment the current begins its decrease.

The datasheet from the MCP73833 chip contains several example curves for the CC-CV charge of LIBs. Although the tests in the datasheets have been carried out on 1700 mAh nominal capacity batteries, the behaviour of the curves are similar in their shapes. The time of charge is, however, different as the $1700 \mathrm{mAh}$ batteries tested in the datasheets take about two hours to be charged whereas the 2600 mAh LIBs tested in this paper take over four hours to charge. Moreover, another major difference resides in the current curve. It is known that the current value during the constant current charge phase is expected to be $1 \mathrm{~A}$. Nevertheless, the test platform works with a constant current of 0.9A. This difference can be explained by the resistor that has been added to measure the current passing through the battery. The value of this resistor has been chosen as $0.5 \Omega$. However, even if the resistance is very low, it induces a small drop in the current. It would be hard to determine precisely the resistor influence on the circuit, but it must be considered. This phenomenon is one more reason to choose to calculate the capacity drawn and thus determine the $\mathrm{SOH}$ on the discharging circuit. Indeed, the discharging circuit is much simpler as it is only composed of resistors. There are thus fewer exterior influences and so fewer errors can occur. 
Journal of Mechanical Design

a)

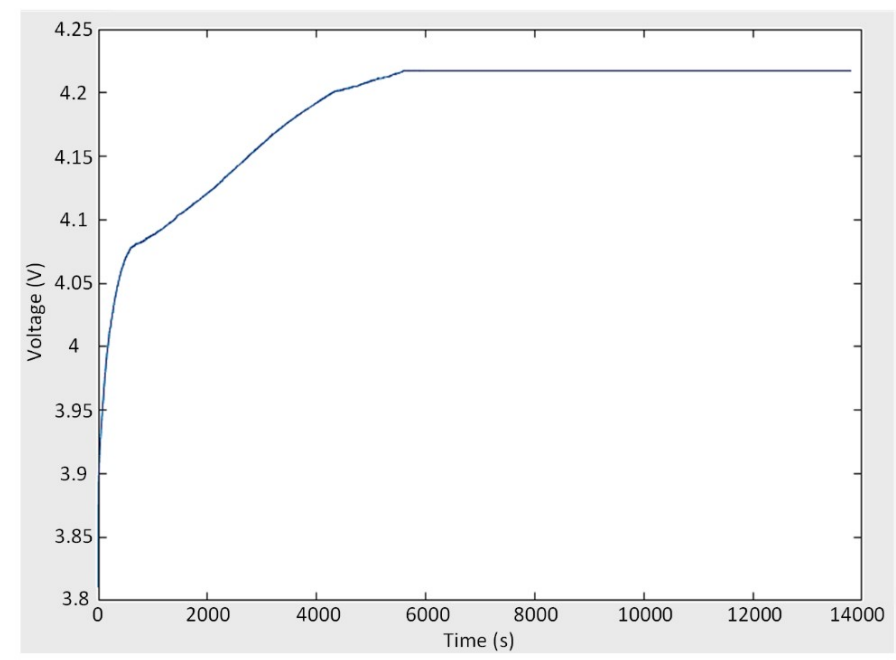

b)

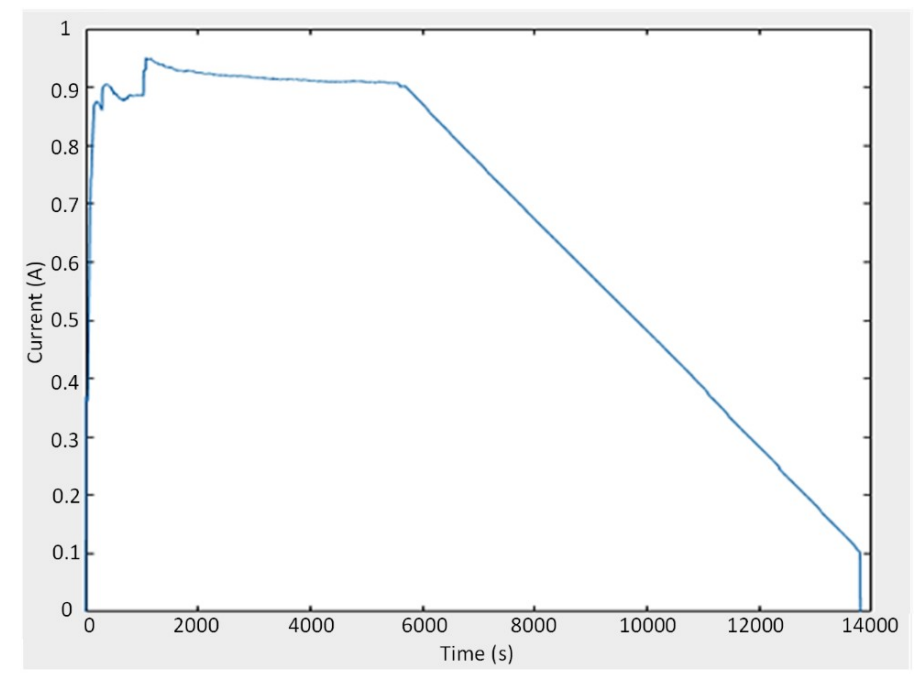

Fig.6 Voltage (a) and current (b) drawn during CC-CV charging

\subsection{Discharging process}

As mentioned in section 3, several circuits for the discharge have been built. This paragraph deals with the discharging of the battery through the three different resistor circuits. As a reminder, the LIB cell can be discharged through either $15 \Omega, 9 \Omega$ or $4.5 \Omega$. 


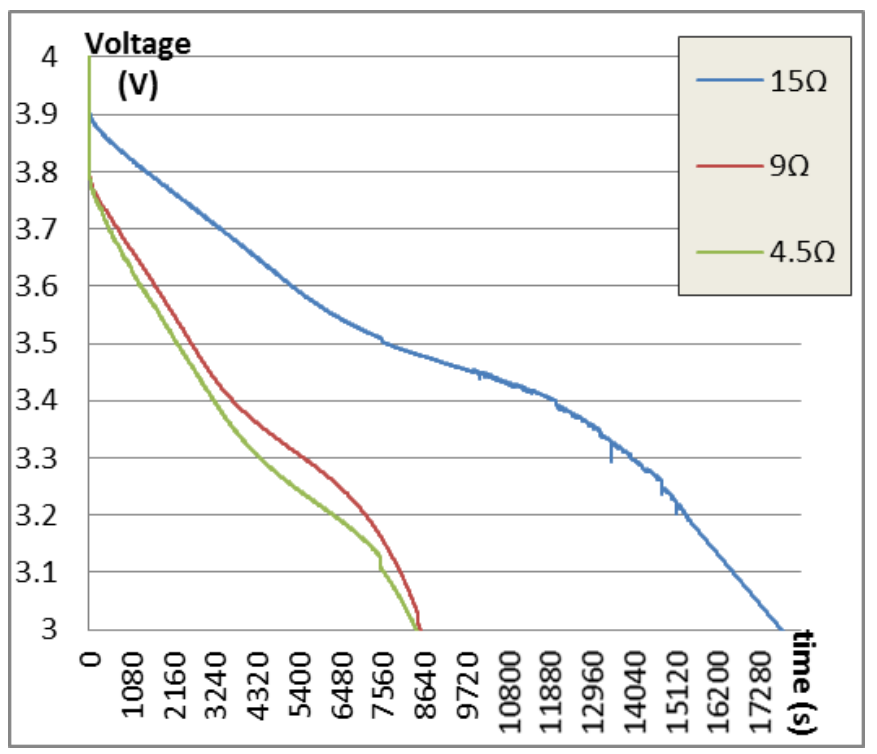

Fig.7 Voltage drawn during the discharging through the three types of resistor circuits

Figure 7 represents the graphs of voltage against time that have been acquired from the test platform. It can be seen that the higher resistance the circuit has, the slower is the discharge. Indeed, while the $4.5 \Omega$ circuit discharges the battery in 8500 seconds, the $9 \Omega$ circuit discharges it in 8519 seconds and the $15 \Omega$ circuit in 18000 seconds. However, even if it appears that the curve of the $9 \Omega$ circuit is always above that of the $4.5 \Omega$ circuit, the difference in the final time that is spent to reach $3 \mathrm{~V}$ is very low, with a 19 seconds difference in time.

The $15 \Omega$ circuit on the other hand is very slow. This can be explained by the rate at which the battery is being discharged. The battery has a nominal capacity of $2600 \mathrm{mAh}$ and according to the current measurements has a current flow passing through it of between 0.28 (at the start) and 0.20 (at the end). As seen earlier, the rate is thus between $0.1 \mathrm{C}$ and $0.08 \mathrm{C}$. With the same technique, the discharge rate of the two other circuits are calculated. With an acquired current between $0.48 \mathrm{~A}$ and $0.34 \mathrm{~A}$, the 
Journal of Mechanical Design

$9 \Omega$ circuit has a rate between $0.18 \mathrm{C}$ and $0.13 \mathrm{C}$. Finally, the current passing through the $4.5 \Omega$ circuit reduces from $0.93 \mathrm{~A}$ to $0.67 \mathrm{~A}$, that is to say a rate reducing from $0.36 \mathrm{C}$ to $0.26 \mathrm{C}$. It can be concluded from these results that the rates of discharge of a battery and the times needed to discharge it are not proportional.

The battery datasheet gives the capacities that can be expected from discharges of several rates above $0.2 \mathrm{C}$. A $0.2 \mathrm{C}$ discharge should have a capacity of $2573 \mathrm{mAh}$, and a $0.5 \mathrm{C}$ discharge, a capacity of $2510 \mathrm{mAh}$. The capacity that has been calculated by the software after the discharge through the $4.5 \Omega$ circuit is $2556.7 \mathrm{mAh}$, which is indeed between the two values. As it is the first cycle the battery was working, and as it respects the values given by the datasheets, it can be considered as the value of $100 \% \mathrm{SOH}$.

For the following experiments, the $4.5 \Omega$ discharge circuit has been chosen as the datasheets of the LIB cells gave information for a discharging rate over $0.2 \mathrm{C}$, which was not the case for the other circuits. Moreover, it indicates that the battery is used at its fullest when discharged at a rate of $0.2 \mathrm{C}$, with an outcome capacity of $2573 \mathrm{mAh}$.

\subsection{Setting time after charge and discharge cycles}

As mentioned in the description of the software, a 30 minute interval is necessary after each charge or discharge. This choice has been made when looking at the batteries behaviour once the process of charge or discharge is stopped. As shown by Figure $8(a)$, once the charging process is completed and the charging circuitry stops delivering current to the battery, a sudden drop in voltage occurs, from $4.2 \mathrm{~V}$ down to 
Journal of Mechanical Design

$4.16 \mathrm{~V}$, and it continues to decrease slowly until $4.15 \mathrm{~V}$. Then, the voltage seems to stabilise. The stabilisation happens 25 minutes after the charge is complete.

A similar phenomenon occurs after the discharging process, as can be seen in Figure 8 (b), which shows an increase in the voltage once the discharging process is stopped. Thus, although the LIB cell has a final voltage of $3 \mathrm{~V}$, its voltage reaches $3.5 \mathrm{~V}$ after a time of 30 minutes, after which the voltage settles.

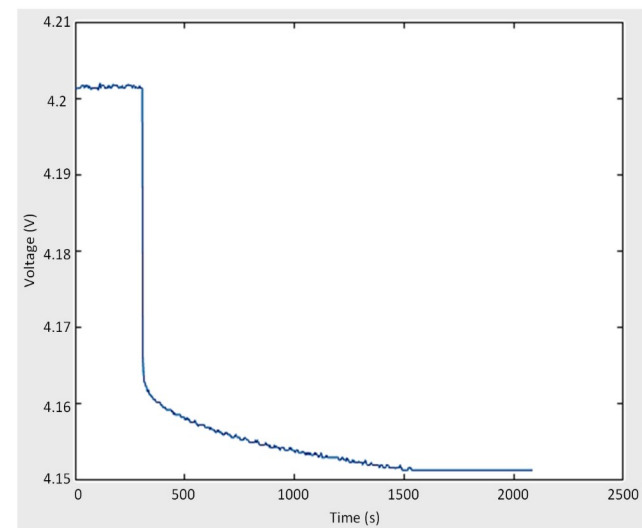

(a)

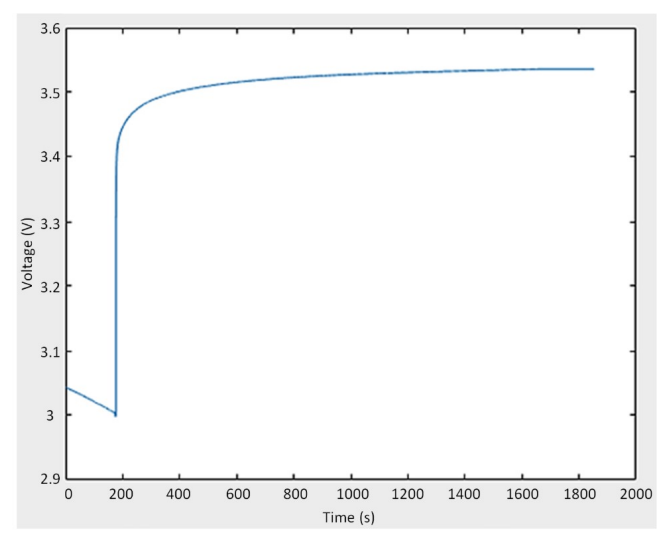

(b)

Fig.8 Graph of voltage against time acquired after a charge (a) and discharge (b)

\subsection{State of health determination}

The $\mathrm{SOH}$ determination occurs after the discharging is completed, as described earlier. The approach has been verified by several experiments. The tests are all made with $2600 \mathrm{mAh}$ nominal capacity LIBs that have been charged beforehand and the $4.5 \Omega$ circuit is used for the discharge.

First, a fresh battery has been tested to see if the resulting SOH would be $100 \%$, as expected. For the batteries that have been used for this test, the datasheet has been taken as a reference for the nominal values. The datasheet [40] indicates that the optimum capacity is $2573 \mathrm{mAh}$ for a discharge rate of $0.2 \mathrm{C}$. However, the circuit that is 
Journal of Mechanical Design

used here does not provide precisely that rate. Indeed, as seen in a previous section, the discharge rate out of this circuit is between $0.36 \mathrm{C}$ and $0.26 \mathrm{C}$. The discharge rate is thus situated between the two values treated by the datasheet: $0.2 \mathrm{C}$ and $0.5 \mathrm{C}$. The capacity out of the battery corresponding to the last case is $2510 \mathrm{mAh}$. The first test led with the $4.5 \Omega$ circuit showed a resulting capacity of $2556.7 \mathrm{mAh}$, which is situated between the two values and thus chosen to be the reference value for the $\mathrm{SOH}$ calculation. So, equation (1) can be precise in the case of this work:

$$
S O H=\frac{Q \max }{2556.7} \times 100 \%
$$

Where $Q_{\text {nominal }}$ has been changed by the value capacity value of a fresh battery. This way, the $\mathrm{SOH}$ will represent the wear of the battery.

Several tests have been carried out on the batteries. First, the fresh battery that had already been tested has been put through several charging/discharging cycles in order to see the evolution of its $\mathrm{SOH}$. Figure 9 shows the different values obtained every 5 cycles.

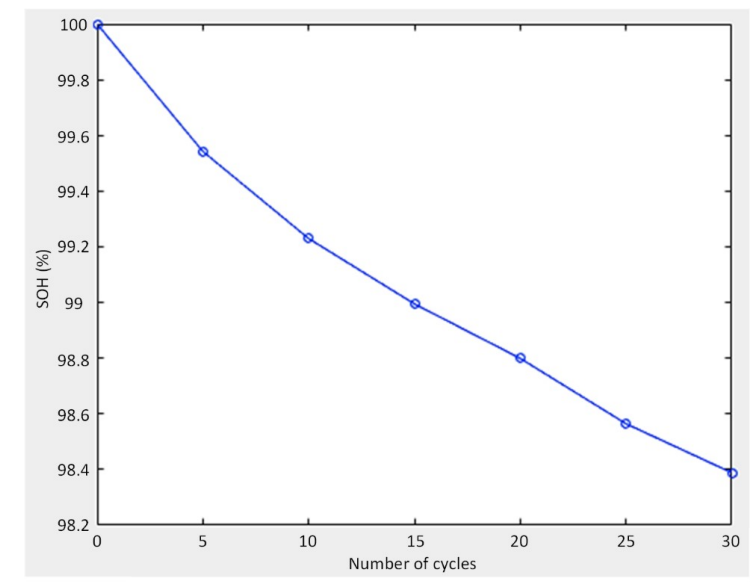

Fig.9 SOH Depending on the number of cycles (from 0 to 30 cycles) 
Journal of Mechanical Design

With the 30 first cycles, it can already be noted that the $\mathrm{SOH}$ does start to decrease and ends up with an $\mathrm{SOH}$ of $98.4 \%$. The battery has thus still a long way to go. The mean value for the $\mathrm{SOH}$ measurements is $99.08 \%$ and the average deviation is 0.56 ; therefore, the true $\mathrm{SoH}$ is $99.08 \pm 0.56 \%$. One of the experiments described in [9] shows that the end-of-life criterion, i.e. a SOH of $80 \%$, is achieved after 370 cycles. To verify this statement, it would be interesting to continue the experiments until the end-of-life of the battery.

Some level of measurement uncertainty is inevitable in a $\mathrm{SOH}$ estimation process due to noise, the sampling period, and other factors. By applying a median filter to reduce the noise and using a consistent sampling frequency of $50 \mathrm{~Hz}$, the accuracy of the SOH estimation has been improved.

\subsection{Energy transfer}

It was mentioned earlier that another discharging circuit was put together. This circuit allows us to discharge one battery into another one. Figures 10 (a) and (b) represent the voltage evolution of the charging and discharging batteries, respectively. For this test, two LIBs of 2600 mAh nominal capacity have been chosen. The first one had been previously charged via the charging circuitry, while the second one had been discharged through the $4.5 \Omega$ resistor circuit. 


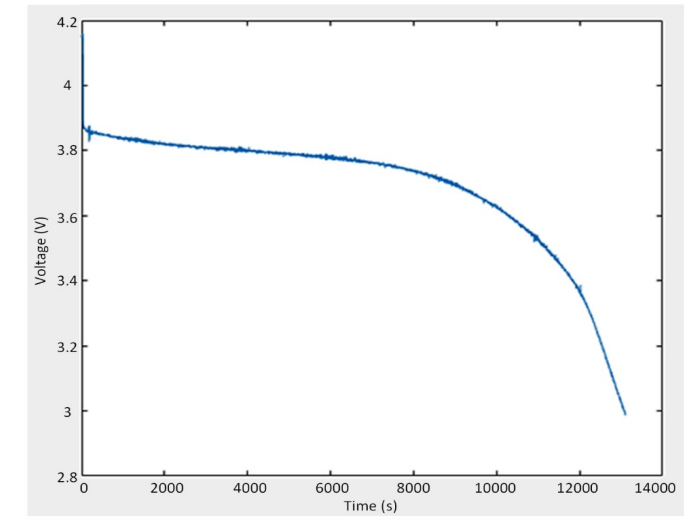

(a)

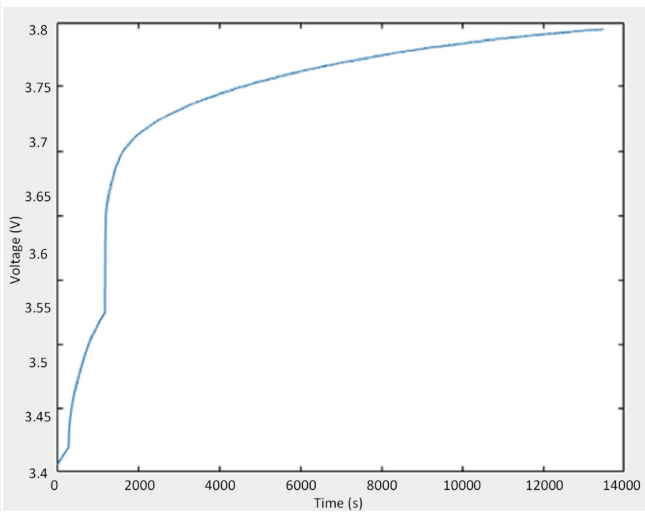

(b)

Fig.10 Voltage drawn of an LIB cell discharging (a) into another LIB cell (b) through the circuitry

The first curve shows a voltage evolution that looks similar to the ones obtained from the discharging circuits previously tested. It can be noted that the draw could be situated between the $9 \Omega$ and the $15 \Omega$ circuits, as the voltage at first drops from its initial value of $4.15 \mathrm{~V}$ to a little less than $3.9 \mathrm{~V}$, and the discharge takes place for more than $3 \mathrm{~h} 30$. On the other hand, the second curve describes what is expected to be the beginning of a charging curve as it does not reach $4.2 \mathrm{~V}$ but only $3.8 \mathrm{~V}$. However, in this case the battery takes much more time to be charged. Indeed, during the time the first battery has discharged, i.e. 13455 seconds, the voltage of the second battery has increased by $0.37 \mathrm{~V}$. This increase happened in the first couple of minutes in the previous tests where the charging circuit was powered by an external $5 \mathrm{~V}$ source. This phenomenon is explained by the lower energy contained in a battery.

A great amount of energy is also lost in the circuitry. Figure 2 showed the circuitry of this discharging method. During the tests, the temperature of the DC/DC converter circuit rose significantly, indicating a heat loss in the process. The loss 
Journal of Mechanical Design

occurring can be calculated by determining how much energy the charging battery actually receives from the discharging battery.

The capacity that the first LIB has given to the circuit is $2559 \mathrm{mAh}$, while the capacity of the second LIB at the end is $989 \mathrm{mAh}$. Thus, the efficiency of the entire circuit is $39 \%$, with $61 \%$ of the energy lost in the different other components of the circuit. The charge of the second battery has then been completed by the charging circuit, and the final capacity has been extracted: $2567 \mathrm{mAh}$. So, the state-of-charge obtained with the circuit was $39 \%$.

This circuit is thus not conclusive for two LIBs, as the losses are too important and it does not permit a full charge.

\section{Further work}

The test platform composed of its circuitry and its software is working and can determine the $\mathrm{SOH}$ of LIBs as expected. It can also be adapted to other types of batteries as the software is flexible.

In addition to the batteries tested in the $\mathrm{SOH}$ determination results section, several other batteries of which the number of cycles was unknown were tested. Many had an $\mathrm{SOH}$ above $80 \%$, which implied they did not reach their end-of-life. Nevertheless, some had an $\mathrm{SOH}$ below the criterion. Thus, they could be considered not suitable for further use in electric devices. However, it was remarked that they still delivered current and voltage and thus still had some capacity left. The discharging/charging circuit that was built to transfer some energy from one battery to another could be used as a way of "recycling" this energy. However, as the results show, the circuit is not conclusive and 
Journal of Mechanical Design

loses more energy than it transmits. Thus, some further work could be done on the circuit by choosing, for example, components that would produce less heat and use less energy.

Moreover, due to a lack of time, only 30 cycles have been carried out to determine the evolution of the $\mathrm{SOH}$. It would be interesting to continue this process until the battery reaches its end-of-life, that is to say an $\mathrm{SOH}$ of $80 \%$.

\section{Conclusion}

A test platform for the determination of $\mathrm{LIBs} \mathrm{SOH}$ has been designed. It has been verified that it calculated coherent values of $\mathrm{SOH}$. The test platform can be adapted to several types of batteries and several rates of discharge can be performed.

The results have pointed out the decrease in the $\mathrm{SOH}$ of an LIB over 30 cycles. Although more cycles should be operated on the battery to have a more accurate curve of the $\mathrm{SOH}$ drop, it has been shown that the battery loses over $1.5 \%$ of its capacity in 30 cycles.

A discharge/charge circuit has also been built to transfer the energy from the discharge of one battery to another battery. However, this circuit suffers from energy loss and poor efficiency.

This paper has shown that the new methods developed give optimal results, allowing them to be applied to future VRP algorithms as well as showing that genetic algorithms can be applied to multiple extensions of the VRP to find optimal results. The algorithm produced can be applied to any combination of the three extensions of the VRP to give a reduced distance in a reverse logistics network. 
Journal of Mechanical Design

Further work could be performed with increases in computational power, which would allow the algorithm to operate quicker so that more complex computations could be performed in a short period of time.

\section{REFERENCES}

[1] Scrosati, B., Garche, J., 2010, "Lithium batteries: status, prospects and future," Journal of Power Sources 195, pp. 2419-2430.

[2] Buchmann, I., 2001, Batteries in a portable world, Richmond, B.C.: Cadex Electronics.

[3]Lithium-Ion Batteries: Fundamentals and Applications, 2016, IEEE Industrial Electronics magazine, 10, pp. 58-59.

[4] Pramanik, S., Anwar, S., 2016, "Electrochemical model based charge optimization for lithium-ion batteries," Journal of Power Sources, 313, 164-177.

[5] Eddahech, A., Briat, O., Vinassa, J., 2014, "Determination of Lithium-ion battery state-of-health based on constant-voltage charge phase," Journal of Power Sources 258, 218-227.

[6] Fellner, J. P., Loeber, G. J., Sandhu, S. S., 1999, "Testing of Li-ion 18650 cells and characterizing/predicting cell performance," Journal of Power Sources 81-82, pp. 867871.

[7] Keil, P., Jossen, A., Charging protocols for lithium-ion batteries and their impact on cycle life - An experimental study with different 18650 high power cells, Journal of Energy Storage Volume 6, PP 125-141, 2016.

[8] Ye, Y. H., Shi, Y. X., Cai, N. S., Lee, J. J., He, X. M., 1999, "Electro-thermal modeling and experimental validation for lithium-ion battery," Journal of Power Sources, 2012, pp. 227-238.

[9] Fleischhammer, M., Waldmann, T., Bisle, G., Hogg, B-I., Wohlfahrt-Mehrens, M., 2015, "Interaction of cyclic ageing at high-rate and low temperatures and safety in lithium-ion batteries," Journal of Power Sources, 274, pp.432-439.

[10] Berecibar, M., Gandiaga, I., Villarreal, I., Omar, N., Van Mierlo, J., Van Den Bossche, P., 2016, "Critical review of state of health estimation methods of Li-ion batteries for real applications," Renewable and Sustainable Energy Reviews 56, pp.572-587. 
[11] Sepasi, S., Ghorbani, R., Liaw, B. Y., 2015, "Inline state of health estimation of lithium-ion batteries using state of charge calculation," Journal of Power Sources 299, pp. 246-254.

[12] Piller, S., Perrin, M. Jossen, A., 2001, "Methods for state-of-charge determination and their applications," Journal of Power Sources 96(1), pp.113-20.

[13] Alzieu, C., Smimite, J. Glaize, H., 1997, "Improvement of intelligent battery controller: State-of-charge indicator and associated functions," Journal of Power Sources, 67 (1-2): 157-161.

[14] Hatzell, K. B., Sharma, A., Fathy, H. K. 2012, "A survey of long-term health modelling, estimation, and control of lithium-ion batteries: challenges and opportunities," American Control Conference (ACC) pp. 584-591.

[15] Büschel, P., Tröltzsch, U., Kanoun, O., 2011, "Use of stochastic methods for robust parameter extraction from impedance spectra," Electrochim Acta, 56(23), pp. 8069-77.

[16] Kozlowski, J. D. 2003, "Electrochemical cell prognostics using online impedance measurements and model-based data fusion techniques," 2003 IEEE aerospace conference proceedings 7, pp3257-70.

[17] Dai, H. F., Wei, X. Z., Sun, Z. C., 2009, "A new SOH prediction concept for the power lithium-ion battery used on HEVs," 2009 IEEE vehicle power and propulsion conference, pp. 1649-1653.

[18] Zhang, C., Liu, J., Sharkh, S.M., 2010, "Identification of dynamic model parameters for lithium-ion batteries used in hybrid electric vehicles, High Technology Letter, 16.

[19] Feng, X., Li, J., Ouyang, M., Lu, L., Li, J., He, X., 2013, "Using probability density function to evaluate the state of health of lithium-ion batteries," Journal of Power Sources, 232, pp. 209-218.

[20] Weng, C., Cui, Y., Sun, J., Peng, H., 2013, “On-board state of health monitoring of lithium-ion batteries using incremental capacity analysis with support vector regression," Journal of Power Sources, 235, pp36-44.

[21] Grube, R. J. 2008, "Automotive battery state-of-health monitoring methods," Wright State University.

[22] Safari, M., Morcrette, M., Teyssot, A., Delacourt, C., 2010, "Life-prediction methods for lithium-ion batteries derived from a fatigue approach," Journal of Electrochemical Society, 157(6): A713. 
[23] Li, Z. Q. Sun, H. Y. Wang, Y. Tang, X. F. Zeng, Y., Wang, Z. D., Zheng, F. Y. 2008, "Effect of hot treatment on mechanical properties and microstructure of a new type AlCu-Li alloy. Journal of Power Sources, 32(4), pp41-45.

[24] Manyika, J., Chui, M., Brown, B., Bughin, J., Dobbs, R., Roxburgh, C., Byers, A. H., 2011, "Big data: The next frontier for innovation, competition and productivity," Mckinsey Global Institute 2011.

[25] Plett, G. L. 2004, "Extended kalman filtering for battery management systems of LiPB-based HEV battery packs," Journal of Power Sources, 134(2), pp.252-261.

[26] Plett, G. L. 2004, "Extended kalman filtering for battery management systems of LiPB-based HEV battery packs", Journal of Power Sources, 134(2), pp.262-276.

[27] Singh, P., Kaneria, S., Broadhead, J., Wang, X., Burdick, J., 2004, "Fuzzy logic estimation of $\mathrm{SOH}$ of $125 \mathrm{Ah}$ VRLA batteries, $10^{\text {th }}$ International Workshop on Computational Electronics, pp.524-31.

[28] Eddahech, A., Briat, O., Bertrand, N., Delétage, J-Y, Vinassa, J-M., 2012, "Behaviour and state-of-health monitoring of Li-ion batteries using impedance spectroscopy ad recurrent neural networks," International Journal of Electrical Power Energy System, 42(1), pp.487-494.

[29] Prasad, G. K., Rahn, C. D., 2013, "Model based identification of aging parameters in lithium ion batteries," Journal of Power Sources, 232, pp.79-85.

[30] Liu, H. W., Xu, W. J., Guo, C., "Study on state of health estimation algorithm for lithium power battery used on pure electric vehicle," Advanced Materials Research, pp.1577-1581.

[31] Sepasi, S., Ghorbani, R., Liaw, B. Y., 2014, "Improved extended Kalman filter for state of charge estimation of battery pack," Journal of Power Sources 255, pp. 368-376.

[32] Zhang J. L., Lee J., 2011, "A review on prognostics and health monitoring of Li-ion battery," Journal of Power Sources 196, pp. 6007-6014.

[33] Schweighofer, B., Raab, K. M., Brasseur, G., 2003, "Modeling of high power automotive batteries by the use of an automated test system," IEEE Transactions on Instrumentation and Measurement, 52 (4), pp.1087-1091.

[34] Guo, Z., Qiu, X. P., Hou, G. D., Liaw, B. Y., Zhang, C. S., 2014, "State of health estimation for lithium ion batteries based on charging curves," Journal of Power Sources 249 , pp. 457-462. 
Journal of Mechanical Design

[35] Raël, S., Hinaje, M., 2013, "Using electrical analogy to describe mass and charge transport in lithium-ion batteries," Journal of Power Sources, 222, pp. 112-122.

[36] ww1.microchip.com/downloads/en/DeviceDoc/22005a.pdf

[37] http://cds.linear.com/docs/en/datasheet/1308abfb.pdf

[38] http://www.ti.com/lit/ds/symlink/ts5a3157.pdf

[39]http://www.ni.com/labview/whatsnew/f/?cid=Paid Search-70131000001Rp0HAASFrance-GrowLVAdoption\&gclid=CLnpmZyp tICFXEWOwodxMAKTg

[40]http://docs-urope.electrocomponents.com/webdocs/1422/0900766b81422bf8.pdf 